\title{
As QUALIDADES FENOMÊNICAS DA EXPERIÊNCIA E O ARguMENTO DO CONHECIMENTO
}

\author{
DANIEL BORGONI
}

\begin{abstract}
Frank Jacksont's knowledge argument defends that physicalism cannot to explain the phenomenal quality of experiences, or qualia. Conscious experiences would involve properties not reducible to physical. The qualia would be the object of phenomenal knowledge, factual knowledge acquired only by experience. My aims are present a formalization that shows the epistemic aspect and the metaphysical aspect of knowledge argument and analyze some of the main objections against it. I will divide these objections in three sorts. The first one refers to objections that deny phenomenal knowledge. The second one refers to objections that accept phenomenal knowledge, but deny that this knowledge refers to nonphysical properties. The third one denies that all physical and functional facts can be known only by physical knowledge. After I have analyzed objections and respective responses, I will conclude that analyzed objections are not decisive against the knowledge argument.
\end{abstract}

Keywords: Consciousness; experience; phenomenal knowledge; qualia; physicalism.

\section{O problema das qualidades fenomênicas da experiência}

Sabemos que somos conscientes, mas não sabemos o que é a consciência. Talvez o principal fator que torne o entendimento da consciência um problema epistemológico e ontológico diga respeito às experiências conscientes. Elas são um grande enigma filosófico, pois não sabemos conciliá-las com o fisicalismo, ${ }^{1}$ tese que, quando aplicada à mente, afirma que a mente é constituída por estados neurais, processos cerebrais ou eventos físicos. Nós não temos uma teoria que explique adequadamente como uma pessoa, ou, mais especificamente, um sistema físico como o cérebro, experiencia um sabor, a felicidade, as sensações de cores, a angústia existencial, uma dor de dente, as coceiras, etc. Como as experiências conscientes se encaixam em nossas teorias filosóficas fisicalistas é um problema sério a ser enfrentado.

A principal dificuldade que filósofos e neurocientistas enfrentam na explicação do que é a consciência é explicar a qualidade subjetiva que aparece à consciência de uma pessoa quando ela tem uma experiência (cf. Chalmers 1996; Crick e Kock 2003). Quando vejo um tomate maduro, tenho uma sensação de vermelho, ou quando tenho uma dor de dente, sinto uma sensação intensa e desagradável na boca. Cada uma dessas experiências aparece à minha consciência de um determinado modo, ou seja, com uma característica qualitativa distintiva que foi apreendida subjetivamente. Esse é o caráter fenomênico das experiências.

Principia 20(3): 393-416 (2016).

Published by NEL — Epistemology and Logic Research Group, Federal University of Santa Catarina (UFSC), Brazil. 
As qualidades da experiência são usualmente denominadas qualia; os qualia caracterizariam as experiências a que pertencem, as nossas dores, os sentimentos de angústia, as pontadas de inveja, as sensações de cores, e assim por diante. Podemos entender o quale de uma dor como o modo como alguém experimenta ou se sente essa dor.

As sensações são, entre os estados mentais que têm um caráter fenomênico, os paradigmas de estados mentais com qualia, porque suas qualidades - o que é sentido - parecem constituir a sua essência. As emoções também parecem possuir qualia, mas elas não são somente classificadas com base em como são sentidas, como é no caso das sensações (cf. Kim 1996, p.157). Assim, no caso das emoções, não parece correto identificarmos este tipo de estado mental com os qualia. Já no caso das sensações, é plausível afirmar que podemos identificar a experiência subjetiva com a sua propriedade (quale).

Nagel (1974) afirma que o caráter subjetivo das experiências parece de impossível conciliação com o fisicalismo, pois esse caráter seria privado e irredutível. Considerando que os qualia têm esse caráter subjetivo, eles são qualidades subjetivas intrínsecas a certos estados mentais e, assim, são relativos a quem está tendo a experiência. Se as qualidades fenomênicas das nossas experiências conscientes só podem ser conhecidas subjetivamente, as qualidades fenomênicas são inescrutáveis sob um ponto de vista de terceira pessoa.

Inúmeros filósofos e filósofas defendem que os qualia são o objeto do conhecimento fenomênico, isto é, conhecimento que não pode ser deduzido das ciências biológicas, químicas ou físicas, pois somente quem tem a experiência poderia conhecê-lo. Haveria, portanto, um hiato entre o conhecimento físico e o conhecimento dos estados mentais conscientes. Aqueles que argumentam a favor desse hiato epistêmico, por vezes, defendem também um hiato metafísico: os qualia seriam propriedades mentais irredutíveis ao mundo físico. Consequentemente, defendem algum tipo de dualismo entre consciência e matéria. O argumento do conhecimento de Frank Jackson $(1982 ; 1986)$, é considerado um dos mais importantes para defender a existência desses dois tipos de hiato, o epistêmico e o metafísico.

Para tratar deste problema central, exporei, em primeiro lugar, a crítica de JackSon $(1982 ; 1986)$ ao fisicalismo, dando uma nova formalização ao argumento do conhecimento com vistas a mostrar o seu aspecto epistêmico e metafísico. Então, exporei algumas das mais importantes objeções que lhe foram opostas e as respostas (contraobjeções) que lhe foram dadas. Pesarei e analisarei objeções e respostas com o objetivo de avaliar qual dos dois lados tem argumentos mais convincentes. Na conclusão, farei um balanço geral deste debate apontando para a posição que me parece mais razoável.

Principia 20(3): 393-416 (2016). 


\section{$\mathrm{O}$ argumento do conhecimento}

Segundo Jackson (1982, p.127) nenhuma quantidade de informações físicas, isto é, informações provenientes das ciências biológicas, químicas, físicas e o que decorre dessas, explicaria completamente as sensações. Essas informações não capturariam os qualia das sensações, como o caráter dolorido das dores ou a vermelhidão do vermelho (redness). Os qualia seriam propriedades não-físicas que dariam a qualidade sentida de certos estados mentais.

Para mostrar isso, Jackson (1982) apresentou dois experimentos mentais, cada um destes uma versão do argumento do conhecimento. O primeiro deles envolve Fred, um rapaz que é capaz de distinguir entre o vermelho-1 e o vermelho-2 do mesmo modo como distinguimos, por exemplo, o azul do amarelo. O segundo experimento e o mais debatido deles trata de pessoas normais e cores familiares, ganhando maior destaque quando Jackson (1986) o reapresenta de forma mais minuciosa. É desse segundo experimento mental, que ficou conhecido como o argumento do conhecimento, que trataremos neste artigo e que reconstruiremos a seguir. A protagonista dessa situação hipotética é Mary, uma neurocientista que sempre viveu num quarto preto e branco. Na época em que Mary vive, sabiam-se todas as informações físicas a respeito da visão humana e, por meio de livros e um monitor que só transmitia imagens em preto e branco, ela se tornou uma especialista em neurofisiologia da visão. Ela sabe como a luz afeta a retina, como a informação é processada no cérebro, enfim, o seu conhecimento físico a respeito da visão humana é completo, isto é, Mary sabe tudo o que há para saber sobre a parte física do que acontece com alguém quando vê. Então, um dia, Mary sai do quarto e vê a cor vermelha de um tomate maduro pela primeira vez. Será que Mary aprenderá mais coisas sobre como o mundo é ao ver o vermelho pela primeira vez? Jackson (1982) afirma que ela aprende algo fundamentalmente novo sobre o mundo: ela aprende como o vermelho é. Mary aprende algo sobre a cor vermelha que somente quem teve a experiência de ver algo vermelho sabe. Se tudo que Mary aprendera sobre a visão humana enquanto estava no quarto não foi suficiente para que ela soubesse como é ver o vermelho, as informações físicas não são suficientes para explicar as sensações. "Ergo, existe mais do que informações físicas, e o fisicalismo é falso" (Jackson 1982, p.130). ${ }^{2}$

$\mathrm{O}$ argumento do conhecimento parte de premissas epistêmicas para chegar à conclusão metafísica de que experiências conscientes envolvem propriedades não-físicas. O novo conhecimento que Mary adquire tem caráter factual e não pode ser deduzido do conhecimento que ela tinha. A partir do hiato epistêmico entre conhecimento físico e conhecimento fenomênico, Jackson infere um hiato metafísico entre consciência e matéria. Contudo, esta passagem não é evidente e, segundo Nida-Rümelin (2010), a utilização da expressão informações físicas no contexto do argumento do conhecimento pode gerar interpretações ambíguas, na medida em que esta pode ser 
interpretada tanto epistemologicamente como ontologicamente. Para eliminar essa possibilidade e, principalmente, tornar explícito como o hiato metafísico é inferido a partir do hiato epistêmico, o formalizamos do seguinte modo:

(1) Antes de sair do quarto preto e branco, Mary tem conhecimento físico completo a respeito da visão humana.

(2) Ao sair do quarto e ver a cor vermelha pela primeira vez, ela adquire conhecimento fenomênico.

(3) Existe conhecimento sobre a visão humana que escapa ao conhecimento físico.

(4) Todos os fatos físicos sobre a visão humana são acessíveis pelo conhecimento físico que Mary tem quando ainda está no quarto.

(5) Ao sair do quarto, Mary aprende um novo fato sobre a visão humana.

(6) Existem fatos não-físicos.

Considerando as premissas (1) e (2) simultaneamente verdadeiras, segue-se a conclusão (3) e temos a versão epistêmica do argumento do conhecimento. Ou seja, o conhecimento físico não é suficiente para explicar o conhecimento fenomênico, ou, conhecimento de como a qualidade sentida de certos estados mentais aparecem para nós. Esse hiato epistêmico entre o domínio físico e o domínio mental só pode ser desfeito quando Mary tem a experiência de ver o vermelho.

A partir do hiato epistêmico, inferimos um hiato metafísico entre consciência e matéria. A premissa (4) indica que todos os fatos físicos são acessíveis pelo conhecimento físico. Assim, quando Mary ainda está no quarto, o conhecimento físico completo de Mary permite a ela conhecer todos os fatos físicos sobre a visão humana. Se o fisicalismo for verdadeiro, todos os fatos físicos sobre a visão humana são todos os fatos sobre a visão humana. Entretanto, a premissa (5) defende que ao ver o vermelho pela primeira vez, Mary aprende um novo fato sobre o mundo, ou seja, um fato sobre a visão humana que estava inacessível a ela quando ainda estava no quarto. Se ela sabia todos os fatos físicos sobre a visão e, ainda assim, aprendeu um novo fato com a sua experiência de cor, pode-se defender a conclusão (6). Se existem fatos não-físicos, o fisicalismo é falso.

\section{Objeções e respostas}

Vimos como o argumento do conhecimento pretende colocar em xeque o fisicalismo. Contudo, ele não é um argumento conclusivo, isto é, não demonstra que Mary aprende um fato não-físico com a sua experiência de cor. O seu caráter inconclusivo é mostrado por meio de uma série de objeções que visam a explicar o que Mary aprende com a sua experiência dentro de uma visão fisicalista da mente, se é que ela aprende

Principia 20(3): 393-416 (2016). 
alguma coisa. Destas, analisaremos algumas das mais importantes objeções que lhe foram opostas do seguinte modo: após expor a objeção, trataremos da respectiva resposta que lhe foi dada. Então, analisaremos objeção e resposta com vistas a avaliar os argumentos mais satisfatórios.

Dividiremos as objeções em três tipos: i) aquelas que negam o hiato epistêmico, ou seja, que afirmam que Mary não adquire conhecimento ao ver o vermelho pela primeira vez, e consequentemente negam o hiato metafísico; ii) as objeções que aceitam o hiato epistêmico, mas que negam o hiato metafísico, isto é, aceitam que Mary adquire um conhecimento novo com a sua experiência de vermelho, mas que afirmam que este conhecimento se refere a um fato físico e; iii) aquelas que negam que todos os fatos físicos e funcionais sobre a cor vermelha podem ser conhecidos por Mary sem que ela tenha a experiência de ver a cor vermelha.

\section{Primeiro tipo de objeção: rejeição ao hiato epistêmico}

Diversos filósofos rejeitam a verdade simultânea das premissas (1) e (2) e, portanto, rejeitam o hiato epistêmico do argumento do conhecimento. Sob esse ponto de vista, Mary não adquire conhecimento quando vê o vermelho pela primeira vez, isto é, não tem nenhum ganho epistêmico com a sua experiência. Dentre esses, Dennett (1991) afirma que o problema com o argumento do conhecimento está na premissa (1), pois nós não sabemos o que é ter todo o conhecimento físico sobre a visão humana. E isso nos leva à intuição errônea de que existe um hiato epistêmico entre conhecimento físico e experiência.

Ora, propõe Dennett (1991, p.399), é igualmente plausível defender um final fisicalista para a história de Mary. Neste final alternativo, quando Mary sai do quarto, seus captores mostram-lhe uma banana pintada de azul com o intuito de enganá-la, haja vista que ela aprendeu que bananas são amarelas, mas nunca viu a cor amarela. Contudo, ela descobre a farsa e explica: eu sabia "exatamente qual a impressão física que um objeto amarelo ou azul (ou verde etc.) teria em meu sistema nervoso. Então, eu sabia exatamente quais pensamentos eu teria" (Dennett 1991, p.399). Dennett (1991, p.400) reconhece que o problema a ser enfrentando por Mary seria identificar as cores que estava vendo com os efeitos neurofisiológicos em seu cérebro via introspecção. Porém, ele afirma que não é difícil imaginar que Mary, por ter um vasto e completo conhecimento físico sobre a visão humana, note que a banana foi pintada de azul, por reconhecer que, quando ela está vendo a banana azul, tem as mesmas reações que um objeto azul causaria em seu cérebro.

Um ponto forte dessa objeção reside na afirmação de que não podemos imaginar o que seria alguém ter todo conhecimento físico sobre a visão humana. Contudo, ela apresenta dois problemas. O primeiro deles é que não demonstra de que modo 
Mary poderia identificar via introspecção os efeitos neurobiológicos que o azul teria em seu cérebro quando estivesse diante da banana azul. O segundo problema é que mesmo se Mary conseguisse identificar a cor da banana pintada de azul, ainda assim, o que está em jogo no argumento do conhecimento não é se Mary consegue identificar uma cor por ter todo conhecimento físico sobre essa cor, mas se ela tem um ganho epistêmico com a sua experiência perceptiva. Ainda que se considere que a estratégia de Dennett (1991, p.400) seja de que a identificação da cor implique num conhecimento prévio da cor, isso não exclui a possibilidade de que Mary adquira conhecimento fenomênico sobre a cor. ${ }^{3}$ Nesse sentido, a objeção de Dennett (1991) não trata da questão central colocada pelo argumento do conhecimento, sendo incapaz de provar que Mary não adquire conhecimento com a sua experiência. Continua plausível afirmar que Mary tem um ganho epistêmico ao ver o vermelho pela primeira vez, pois podemos sustentar as verdades simultâneas das premissas (1) e (2) e defender que existe conhecimento sobre a visão humana que não se restringe ao conhecimento físico.

A objeção que analisaremos agora é a hipótese da habilidade de David Lewis (2002[1988]). Contra a premissa (2) do argumento do conhecimento, essa hipótese propõe que, ao ver o vermelho pela primeira vez, Mary não adquire um conhecimento proposicional, isto é, conhecimento de fato, mas uma habilidade. Segundo Lewis (2002[1988], p.292), podemos entender como é ter uma experiência como a habilidade de se colocar em um estado representativo dessa experiência. Existe assim uma conexão entre a habilidade e o ponto de vista de quem experimenta; quando exercemos essa habilidade, adotamos o ponto de vista de primeira pessoa. Desse modo, ter uma experiência implica em adquirir as habilidades de recordar, imaginar e reconhecer uma experiência. Saber como é uma experiência é a posse de habilidades recognitivas. Então, o saber como é a experiência "não é a posse de nenhuma classe de informação, seja ordinária ou peculiar (...) não é um saber que [knowingthat]. É um saber como [knowing-how]" (Lewis 2002[1988], p.293).

Por exemplo, não podemos ter a habilidade de recordar, imaginar e reconhecer o coentro, se nunca experimentamos coentro. Do mesmo modo que alguém que nunca provou coentro, ao provar, adquire as habilidades de recordar, imaginar e reconhecer o coentro, quando Mary vê pela primeira vez o vermelho de um tomate, ela adquire habilidades recognitivas. Ela não adquire um conhecimento proposicional, isto é, um saber que, ela adquire uma habilidade, um saber como recordar, imaginar e reconhecer o vermelho. Ou seja, o que está envolvido na experiência de Mary não é uma compreensão de fatos, mas a aquisição de habilidades. Assim, sob esse ponto de vista, não precisamos postular um conhecimento fenomênico para explicar o que Mary aprende com a experiência e, por conseguinte, não precisamos postular fatos não-físicos.

Parece-me certo que Mary adquire habilidades recognitivas com a sua experiência

Principia 20(3): 393-416 (2016). 
de cor. Contudo, a hipótese de Lewis (2002[1988]), por não demonstrar que habilidades são tudo o que Mary adquire com a sua experiência, dá margem a respostas que defendem que Mary tem um ganho epistêmico ao ver o vermelho. Brie Gertler (2006, p.114) argumenta que um dos problemas com a hipótese da habilidade é especificar uma habilidade que Mary ganha no momento em que tem a experiência de ver o vermelho. A filósofa defende que no instante em que Mary sabe como é o vermelho, ela ainda não tem nenhuma habilidade, por exemplo, de lembrar-se do vermelho. Desse modo, é problemático identificarmos o saber como é ver o vermelho com uma capacidade recognitiva. Mary precisaria saber antecipadamente como é o vermelho para que adquirisse a habilidade de reconhecer o vermelho. Ao que parece, as habilidades recognitivas que Mary adquire ao ver o vermelho pela primeira vez dependem de se saber como é o vermelho, e, assim, não podemos reduzir ou explicar esse saber em termos daquelas.

Chalmers (1996, p.145) também discorda que habilidades são tudo o que está envolvido na experiência de Mary. Ao contrário de alguém que sabe todas as informações físicas sobre bicicletas, e quando aprende a andar de bicicleta, adquire somente habilidades, a situação é diferente no caso de Mary. Quando Mary vê o vermelho, ela elimina diversas hipóteses de como seria ver o vermelho, tendo em vista que a sua experiência de cor limitou as possibilidades epistêmicas. Ou seja, agora ela sabe como é ver o vermelho, que o vermelho é como isto e não como aquilo. Mediante tais respostas, parece-me razoável supor que além de habilidades, Mary aprende um conhecimento novo acerca de como o mundo é ao ver o vermelho pela primeira vez. Contrariamente ao que Lewis (2002[1988]) afirma, o que Mary aprende não é um saber como, é um saber que. Desse modo, a hipótese da habilidade não fecha a lacuna epistêmica do argumento do conhecimento.

Assim como Lewis (2002[1988]), Paul Churchland (1985) nega que Mary adquire conhecimento proposicional com a sua experiência de cor. Mas, diferentemente da hipótese da habilidade, Churchland (1985, p.23) defende que Mary adquire conhecimento por familiaridade ou contato (acquaintance knowledge). Ele afirma que o conhecimento que Mary adquire sobre a visão humana quando está trancada no quarto (conhecimento físico) é uma questão de saber um conjunto de proposições, o tipo de conhecimento que está escrito em livros de neurociência. Já o conhecimento que Mary adquire ao sair do quarto "parece ser uma questão de ter uma representação de vermelhidão em algum meio pré-linguístico ou sublinguístico de representação para variáveis sensoriais (...) ou algo nessa linha" (Churchland 1985, p.23) Ou seja, quando Mary está trancada no quarto e quer saber sobre a sensação de ver o vermelho, o que está acessível a ela é conhecimento a respeito dos processos cerebrais que ocorrem quando alguém vê a cor vermelha. Quando ela sai e vê a cor vermelha, ela tem acesso também ao conhecimento por familiaridade da sensação de ver o vermelho. No entender de Churchland (1985, p.24), a diferença entre o conhecimento 
que Mary adquire no quarto e o conhecimento de uma pessoa que não sabe nada de neurociência, mas que já viu o vermelho, não está no que é conhecido por cada um, mas nas maneiras diferentes que cada um tem de conhecer a mesma coisa. Desse modo, não precisamos dos qualia para explicar a sensação de vermelho de Mary.

Em outra objeção que Churchland (1985, pp.25-8) apresenta contra o argumento do conhecimento, ele afirma que a neurociência do futuro pode modificar os conceitos que temos sobre a mente de tal forma que afete a apreensão introspectiva dos nossos estados internos e, consequentemente, reflita em nossa capacidade de imaginação. Mesmo que Mary não tenha tido a sensação de vermelho, o seu vasto conhecimento permitiria a ela "ser capaz de se imaginar estando nos estados corticais relevantes e imaginar o vermelho com bastante sucesso" (Churchland 1985, p.26).

Para tornar sua objeção mais convincente, ele apresenta um exemplo real de pessoas que podem imaginar coerentemente sons. Pessoas que não são educadas musicalmente ouvem acordes musicais como um todo e não reconhecem as estruturas internas e os seus elementos. Já os músicos conseguem ouvir acordes como grupos ou identificar as notas. O inverso é também verdadeiro:

[...] se um conjunto de notas é verbalmente especificado, uma pianista ou um guitarrista treinado podem identificar os acordes e lembrar seus sons em sua imaginação auditiva. Além disso, um indivíduo realmente habilidoso pode construir, em sua imaginação auditiva, o som de um acorde que ele pode nunca ter ouvido antes. (Churchland 1985, p.26)

Baseado nisso, ele levanta a seguinte questão: por que isso não poderia acontecer com as sensações de cor? Churchland (1985, p.26) reconhece que se poderia objetar que, enquanto acordes musicais são conjuntos de elementos estruturados audivelmente, sensações de cor não são. Entretanto, ele defende que o avanço da neurociência poderia revelar que sensações de cor têm uma estrutura interna comparável aos acordes musicais e que, de modo algum, Jackson (1982) tem como vetar tal possibilidade.

Diversas respostas foram apresentadas contra essas objeções de Churchland (1985). No que diz respeito à primeira destas objeções, Jackson (1986, pp.293-4) afirma que, o que está em jogo não é o tipo, espécie ou modo de conhecimento, mas que a questão crucial envolvida em seu argumento é se o que há de físico é tudo o que há para saber. Torin Alter (2007) e Gertler (1999) também discordam que a hipótese da acquaintance responde adequadamente ao argumento do conhecimento. Para Alter (2007, p.400), o problema é que acquaintance pode se referir, às vezes, ao conhecimento e, outras vezes, à experiência. Se aceitarmos o primeiro sentido, isto é, se fizermos uma interpretação epistêmica, não está claro se o conhecimento por familiaridade que Mary adquire ao ver o vermelho não inclui componentes factuais. Se aceitarmos o segundo sentido, ou seja, a interpretação experiencial, a hipótese de Churchland (1985) trivializa a afirmação de que Mary aprende algo ao 
ver o vermelho pela primeira vez, tendo em vista que ninguém nega que ela tem novas experiências ao sair do quarto. No entender de Gertler (1999, p.327), falta poder explicativo à hipótese da acquaintance, pois, enquanto essa enfatiza a diferença epistêmica entre conhecimento físico e conhecimento por familiaridade, Churchland (1985) não explica porque isso ocorre. Nesse caso, o dualismo oferece uma resposta mais convincente para essa disparidade recorrendo aos qualia.

A meu ver, assim como a hipótese da habilidade, a hipótese do conhecimento por acquaintance acima exposta estabelece um ponto correto, mas incompleto; e, nessa incompletude, a objeção abre uma brecha para a conclusão antimaterialista do argumento do conhecimento. Há ainda um segundo problema sério com essa objeção. Considerando que Mary adquire somente conhecimento por acquaintance com a sua experiência de cor, esse conhecimento pode ter componentes factuais. Ora, se abrirmos essa possibilidade, Mary aprende um novo fato sobre a cor vermelha ao ver o tomate maduro, colocando em xeque o fisicalismo.

A respeito da outra objeção de Churchland (1985, pp.25-8) ao argumento do conhecimento, Jackson (1986, p.295) a responde afirmando que a imaginação não está em questão em seu argumento. Se o fisicalismo for verdadeiro, Mary não precisará da imaginação, pois ela já tem a informação crucial acerca da experiência do vermelho. Quanto a essa objeção, parece-me que Jackson (1986) está certo ao afirmar que o seu argumento é uma questão de conhecimento e não de imaginação. Essa resposta, entretanto, não resolve o ponto, pois a objeção em questão certamente também trata da questão do conhecimento. O que podemos e o que não podemos conhecer? Que impactos pode uma neurociência mais desenvolvida trazer para nossas concepções sobre os fenômenos mentais? A meu ver, é certo que não está em nosso alcance estabelecer de antemão o que uma neurociência do futuro pode e não pode dizer. Assim, entendo que Churchland (1985) tem razão ao afirmar que poderia ocorrer uma mudança radical nas nossas concepções que envolvem fenômenos mentais. Por tratar-se de uma questão a ser respondida empiricamente, o argumento de conhecimento para negar tal possibilidade não é aceitável. No futuro, a neurociência pode estabelecer o materialismo. Mas é preciso aceitar que, no estágio atual, esse materialismo não passa de uma aposta.

Outra objeção ao hiato epistêmico entre conhecimento físico e conhecimento fenomênico foi oferecida por Nigel Thomas (1998). ${ }^{4}$ Ele ataca a premissa (1) do argumento do conhecimento, defendendo que não se adquire conhecimento científico somente por meio de descrições, regras e teorias. Assim, conhecimento físico não é apenas uma questão de conhecimento teórico, mas depende de prática e habilidade. Do mesmo modo que Polanyi (1962) defende a necessidade do conhecimento tácito ${ }^{5}$ e Kuhn (2011[1970]) a necessidade dos exemplares ${ }^{6}$ na transferência de conhecimento científico para os estudantes, Thomas defende que o "conhecimento científico da cor (...) não pode ser completo na ausência de reconhecimento extensivo e habi- 
lidades imaginativas (...) que podem ser adquiridas somente através de experiência passada diretamente" (1998, p.3, grifos nossos). Ou seja, ter a experiência visual de cores é fundamental para se entender as cores. Portanto, Mary não pode entender todo o conhecimento físico sobre a visão humana de cores enquanto estiver trancada no seu quarto, por dispor apenas de descrições e teorias sobre a visão humana. Faltam-lhe as habilidades recognitivas necessárias "que permitem a alguém saber o que significam os termos de cor" (Thomas 1998, p.6). Desse modo, embora Mary possa ter todo conhecimento científico discursivo a respeito da visão humana, o argumento do conhecimento falha, não porque ela aprende algo novo quando vê o vermelho pela primeira vez, mas porque a premissa (1) é incoerente.

A meu ver, a crítica de Thomas (1998) não ataca o que está em jogo no argumento do conhecimento, isto é, o que Mary aprende quando vê o vermelho pela primeira vez. Isso envolve o problema de explicar a natureza da qualidade sentida da sua experiência visual da cor vermelha. Desse modo, mesmo se considerarmos que a experiência é fundamental para que Mary adquira o conhecimento científico necessário para compreender as cores, o problema permanece: qual a natureza do conhecimento adquirido quando Mary vê o vermelho pela primeira vez que não se reduz ao conhecimento que Mary adquire quando está no quarto? Se se permite que Mary adquira conhecimento fenomênico com a sua experiência de cor, não se elimina a hipótese dos qualia. Pelo fato de que a objeção em questão não ataca o problema central posto por Jackson $(1982 ; 1986)$, ela me parece ineficaz contra o argumento do conhecimento.

A última objeção ao hiato epistêmico proposto por Jackson (1982; 1986) entre conhecimento físico e conhecimento fenomênico que trataremos é apresentada pelo proponente do argumento do conhecimento. Em autocrítica, Jackson (1998; 2003; 2007) passa a defender que o argumento do conhecimento está errado. Jackson (1998, p.76) afirma que o conhecimento sobre como é o vermelho pode ser deduzido por Mary quando ainda está presa no quarto. E a forte intuição de que Mary aprende algo novo com a sua experiência de cor se deve ao modo atípico como adquirimos informações das nossas experiências sensoriais. ${ }^{7}$ A resposta fisicalista ao argumento do conhecimento, que evidenciaria essa intuição epistêmica, "repousa na abordagem representacionalista da experiência sensorial" (Jackson 2003, p.252). A teoria representacional explicaria como "a natureza da experiência de cor deve seguir possivelmente a priori de um relato físico completo de como o mundo é" (Jackson 2003, p.263).

De forma geral, o representacionalismo procura entender as experiências perceptivas em termos intencionais, ou seja, experiências têm um conteúdo intencional que representa os objetos e eventos do mundo de determinada maneira (cf. Fish 2010, p.67). Esse conteúdo é determinado por referência aos objetos da experiência e, como podemos incorrer em erro na percepção, isto é, o que é percebido pode não existir, 
como nos casos de alucinação, os objetos da percepção são tratados como objetos intencionais.

O representacionalismo adotado por Jackson (2003; 2007) é o strong intentionalism, isto é, aquele que defende a exhausted thesis: "para cada caráter fenomênico $P$ existe algum conteúdo $C$ tal que o estado [mental] com $P$ não é nada mais que um estado [mental] fenomênico com um conteúdo C" (Seager e Bourget 2007, p.263). Ou seja, o conteúdo representacional de uma experiência perceptiva seria suficiente para explicar o seu caráter qualitativo. Desse modo, o que aparece à consciência de uma pessoa nas experiências perceptivas não seriam propriedades intrínsecas à própria experiência, mas propriedades dos objetos representados na experiência, ou propriedades intencionais. Isso é mostrado, segundo Jackson (2003, p.258), pela análise que Harman (1990) faz da transparência das experiências. Por isso, a reconstruiremos a seguir.

Se uma pessoa, digamos Eloísa, vê uma árvore diante dela, o conteúdo da sua experiência é a árvore, que é representada de certa maneira para Eloísa, por exemplo, contendo caule marrom, folhas verdes e estando à sua direita. Mas do que Eloísa é consciente em sua experiência visual? Para Harman (1990, p.35) aqueles que defendem a existência de itens internos e mentais, como propriedades intrínsecas da experiência acessíveis à consciência de Eloísa, não diferenciariam as propriedades do objeto representado na experiência das propriedades da representação deste objeto. Em defesa de seu ponto de vista ele recorre à tese da transparência da experiência. Analisando a experiência de Eloísa, Harman (1990, p.36) afirma que o conteúdo da representação mental de Eloísa não é algo que está na mente, mas algo que está no mundo, de tal modo que, o que é experienciado por Eloísa é somente a árvore com as suas respectivas características, uma vez que, nenhuma característica da árvore é experimentada por ela como uma característica intrínseca da sua experiência. Ou seja, nada na experiência visual de Eloísa "lhe revela as propriedades intrínsecas da experiência em virtude das quais possui o conteúdo que possui" (Harman 1990, p.38). Voltando sua atenção para a sua experiência perceptiva, isto é, estando introspectivamente consciente do conteúdo da sua experiência, Eloísa estará consciente somente das características representacionais ou relacionais da sua experiência. Se somente as propriedades representadas são reveladas a Eloísa, nenhum objeto mental e interno que daria à experiência perceptiva a sua qualidade sentida é para ela revelado. Se o que aparece a ela é apenas o conteúdo representacional, é esse conteúdo que determina o caráter fenomênico envolvido em sua percepção. Por conseguinte, as características qualitativas da experiência são os conteúdos representados na experiência.

Assim, ao defender o acesso consciente às propriedades intrínsecas da experiência, o argumento do conhecimento falha, pois, pela transparência da experiência, nada sobre essas é revelado a Mary quando ela vê o vermelho. Jackson (2003, p.271) 
afirma que, se Mary pensar que aprendeu algo novo sobre como as coisas são ao ver o vermelho, ela estará equivocada, pois não lhe é revelada nenhuma característica intrínseca da sua experiência. O que caracteriza a sua experiência são somente propriedades intencionais fisicamente explicáveis e, portanto, já conhecidas por Mary quando estava no quarto. Assim, a qualidade sentida do vermelho presente na experiência visual de Mary não diz respeito a novas propriedades. Ao ver o vermelho pela primeira vez, Mary "está em um novo tipo de estado representacional diferente daqueles que estava anteriormente" (Jackson 2003, p.271). Então, saber como é ver o vermelho é saber como é estar nesse estado representacional, e isto, no entender de Jackson, é "ter a habilidade de reconhecer, imaginar e lembrar esse estado" (2003, p.271). Desse modo, Mary não adquire conhecimento fenomênico ao ver o vermelho pela primeira vez. Ela adquire uma habilidade recognitiva e, desse modo, Jackson (2003) associa a hipótese da habilidade com a teoria representacional.

Peacocke (1983) discorda que o tipo de representacionalismo defendido por Jackson $(2003 ; 2007)$ possa explicar o caráter subjetivo da experiência e, portanto, possa explicar tudo o que a experiência nos revela. Um dos argumentos que Peacocke (1983, pp.12-3) apresenta é o seguinte: vamos supor que estamos posicionados em frente à aresta que une duas paredes perpendicularmente. Ambas as paredes estão pintadas com um amarelo de mesmo tom, brilho e saturação e uma delas está mais iluminada do que a outra. A nossa experiência pode representar as duas paredes sendo da mesma cor amarela, mas também é um fato sobre nossa experiência visual que uma delas parece ter uma cor amarela clara e a outra parece ter uma cor amarela escura. Em outras palavras, temos consciência de que as paredes são da mesma cor, mas também temos consciência de que uma parede parece mais clara e a outra parede parece mais escura. A aparência de que uma parede é mais clara do que a outra é claramente um fato sobre a nossa experiência. Desse modo, nossas experiências perceptivas parecem nos ensinar que, além de representarem as propriedades dos objetos, elas apresentam também suas aparências e, assim, devem existir propriedades não-representacionais. ${ }^{8}$

Hill (2011) também questiona o tipo de representacionalismo de Jackson (2003; 2007). Quando passamos o dedo sobre uma superfície, temos consciência da propriedade da superfície, sua aspereza. Contudo, voltando a nossa atenção para o que ocorre em nossos dedos, teremos consciência das sensações, o que não é o mesmo que dizer que "sempre temos consciência das sensações de tato quando estamos examinando um objeto por meio do tato" (Hill 2011, p.89). Assim, conforme direcionamos nossa atenção, podemos perceber as propriedades dos objetos externos (a aspereza da superfície) ou objetos internos. Ora, isso coloca em xeque a tese da transparência da experiência, uma vez que a nossa introspecção parece nos colocar em contato com outras propriedades, além das propriedades representacionais.

Frente a estas críticas, parece-me que o tipo de representacionalismo que vimos 
não oferece uma explicação satisfatória para o caráter subjetivo da experiência. Somente as propriedades representadas na experiência não explicam porque a experiência também pode revelar à introspecção as aparências dos objetos representados - essas são um fato sobre as experiências. Ora, se o representacionalismo do qual tratamos não explica tais aparências, devem existir outras propriedades além das propriedades representadas na experiência. Desse modo, é razoável afirmar que essa teoria não explica completamente a nossa experiência perceptiva.

Mediante o exposto, discordo da posição de Jackson (2003) e Harman (1990) de que quem defende a existência de itens mentais e internos acessíveis à consciência na experiência perceptiva estaria confundindo as propriedades do objeto representado na experiência com as propriedades da representação desse objeto (propriedades intrínsecas da experiência), avalizando as últimas em detrimento das propriedades intencionais. Ao que parece, existe uma confusão, mas não porque temos a ilusão epistêmica de que existem propriedades das experiências, mas sim porque nossa experiência perceptiva pode nos revelar outras propriedades além das representacionais, que podem ser os qualia.

Então, parece-me razoável afirmar que a experiência de cor de Mary não pode ser explicada totalmente pelo tipo de representacionalismo analisado. Ou seja, a característica qualitativa do vermelho não pode ser reduzida ao conteúdo representado na experiência de ver o vermelho. Se abrirmos a possibilidade de que existam outras propriedades além das representacionais, o conteúdo da experiência não reduzido às representações pode ser as propriedades intrínsecas da experiência. Então, a objeção que vimos não é decisiva contra o argumento do conhecimento.

Em resumo, sob meu ponto de vista, nenhuma das objeções que vimos explicam satisfatoriamente o que Mary experiencia quando vê o vermelho pela primeira vez. Vimos que a objeção de Dennett (1991) não ataca a questão central do argumento do conhecimento. A hipótese da habilidade de Lewis (2002[1988]) apenas complementa a explicação do que Mary aprende com a experiência. A primeira objeção de Churchland (1985) e a objeção de Thomas (1998) parecem antes confirmar, que negar que Mary tem um ganho epistêmico com a sua experiência de cor. O caso da outra objeção de Churchland (1985) que vimos é mais complexo. Embora abra as portas para o fisicalismo, ela não é decisiva contra o argumento do conhecimento, pois estabelece somente uma possibilidade futura. Assim como não há como negar a possibilidade de êxito da neurociência, também não há como garantir seu êxito. Por fim, a objeção de Jackson (1998; 2003; 2007) ao argumento do conhecimento, baseada na teoria representacionalista que vimos não explica satisfatoriamente o que está presente à consciência de Mary na sua experiência perceptiva. Desse modo, pareceme que negar que Mary tenha um ganho epistêmico não é uma boa estratégia contra o argumento do conhecimento. 


\section{Segundo tipo de objeção: rejeição ao hiato metafísico}

As objeções ao argumento do conhecimento que abordaremos a seguir são usualmente conhecidas como materialismo a posteriori, uma vez que aceitam o hiato epistêmico, mas rejeitam o hiato metafísico do argumento do conhecimento. Essas objeções atacam a premissa (5), defendendo que Mary adquire conhecimento novo com a sua experiência de vermelho, mas que este conhecimento corresponde a um fato já conhecido. Ou seja, quando Mary sai do quarto e vê o vermelho pela primeira vez, ela conhece um fato físico sob um novo modo de apresentação.

Um dos primeiros filósofos a levantar esse tipo de objeção contra o argumento do conhecimento foi Michael Tye (1986). ${ }^{9}$ Antes de entrarmos efetivamente em sua objeção, consideremos os enunciados este líquido é água e este líquido é $\mathrm{H}_{2} \mathrm{O}$. Não podemos deduzir que ambos os enunciados expressam o mesmo fato, pois a cognoscibilidade de certas verdades necessárias depende da experiência - é estabelecida empiricamente. (cf. Kripke 1980). Água $=\mathrm{H}_{2} \mathrm{O}$ é uma verdade necessária que não é a priori. Essa identidade só pôde ser estabelecida a posteriori, uma vez que, não existe nenhuma conexão necessária a priori entre o pensamento do que é a água (líquido incolor, que preenche os rios, etc) e o pensamento do que é $\mathrm{H}_{2} \mathrm{O}$ (dois átomos de hidrogênio e um de oxigênio). Ao concebermos a água como um líquido, estamos concebendo-a sob um modo contingente de apresentação de $\mathrm{H}_{2} \mathrm{O}$, tendo em vista que tudo que precisamos para que algo seja água é de uma quantidade de moléculas de $\mathrm{H}_{2} \mathrm{O}$.

De modo análogo à identidade estabelecida a posteriori entre água e $\mathrm{H}_{2} \mathrm{O}$, Tye (1986, p.12) defende que a identidade entre a qualidade subjetiva das experiências e propriedades físico-químicas seria estabelecida por meio da experiência. ${ }^{10}$ Enquanto estiver no quarto, Mary pode saber todo conhecimento físico sobre a visão humana, mas, por depender da experiência de ver o vermelho, ela não conseguirá deduzir o conhecimento fenomênico do conhecimento físico. Em outras palavras, sem a experiência ela não consegue desfazer o hiato epistêmico entre ambos os conhecimentos. Ao sair do quarto e ver o vermelho pela primeira vez, Mary pode estabelecer a identidade entre o modo de apresentação fenomênico do vermelho e o modo de apresentação físico do vermelho. Estabelecida a posteriori a identidade entre o fenomênico e o físico, Mary aprende um conhecimento novo, mas não um fato novo sobre o mundo, pois o modo de apresentação fenomênico do vermelho corresponde a um fato que ela, por ter todo conhecimento físico sobre a visão humana, já conhecia. Então, nega-se a premissa (5), uma vez que, conhecimento fenomênico e conhecimento físico se referem a um fato físico. Em suma, somente por meio da experiência, Mary pode descobrir que o conhecimento adquirido dentro do quarto e o conhecimento adquirido com a sua experiência de cor se referem a um mesmo fato físico. Se Mary não conhece nenhum fato novo ao ver o vermelho, não se segue a conclusão (6) do 
argumento do conhecimento, uma vez que não precisamos supor fatos não-físicos.

Diversas críticas foram apresentadas contra o materialismo a posteriori de Tye (1986). No meu entender, uma das mais convincentes é a de Brian Loar (2002 ). Embora Loar também seja um materialista a posteriori, ele entende que a analogia que Tye (1986) propõe entre água- $\mathrm{H}_{2} \mathrm{O}$ e domínio mental-domínio físico não se sustenta. Lembremos que, quando concebemos a água como um líquido incolor, inodoro e que preenche os oceanos, estamos concebendo-a sob um modo contingente de apresentação, pois, para que algo seja água, tudo que se exige é que tenhamos certa quantidade de moléculas de $\mathrm{H}_{2} \mathrm{O}$. Entretanto, quando Mary vê o vermelho pela primeira vez, não existe nenhuma contingência no modo como ela experiencia o vermelho, na medida em que ela o concebe diretamente, isto é, "ela tem uma compreensão direta da propriedade envolvida em sua nova informação" (Loar 2002[1997] p.297, grifos do autor).

A resposta de Loar (2002[1997]) é decorrente da resposta de Kripke (1980) contra os teóricos da identidade que defenderam que a dor $=$ fibras- $C$ do sistema nervoso quando estimuladas. Kripke argumentou que essa explicação não capturaria a essência da dor, pois a sua natureza se mostra na sensação de dor. A dor "não é selecionada por uma das suas propriedades acidentais; antes ela é selecionada pelas propriedades de ser a própria dor, pelas suas qualidades fenomênicas imediatas" (Kripke 1980, p.152). Do mesmo modo, Loar argumentou que, contrariamente ao que se verifica no caso da água, a nova concepção do vermelho que Mary adquire com a experiência não é mediada por um modo contingente de apresentação de uma propriedade física.

A meu ver, a objeção de Tye (1986) ao argumento do conhecimento não é convincente. Parece-me correto afirmar que quando Mary vê o vermelho, ela aprende como é algo vermelho diretamente. O vermelho aparece à consciência de Mary de modo direto, ou seja, seleciona uma propriedade essencialmente. Assim, o modo de apresentação fenomênica do vermelho não pode estar se referindo a um fato já conhecido por Mary enquanto ela estava trancada no quarto. Ora, se Mary aprende um novo fato com a sua experiência, é lícito defender o hiato metafísico entre consciência e matéria proposto por Jackson (1982; 1986).

Todavia, a resposta que vimos contra a objeção de Tye (1986) não atinge o tipo de materialismo a posteriori de Loar (2002[1997]), baseado nos conceitos fenomênicos: concepções das qualidades das experiências perceptivas e sensoriais que formamos quando as discriminamos introspectivamente. Diferentemente dos conceitos físicos, conceitos fenomênicos derivam suas referências a partir de um ponto de vista de primeira pessoa, ou seja, são formados com base na introspecção. Quando vejo o vermelho de um tomate maduro, formo o conceito fenomênico sensação de vermelho. Esse conceito difere do conceito vermelho, pois, enquanto esse último geralmente qualifica objetos, o conceito fenomênico sensação de vermelho qualifica a sensação que tive ao ver o vermelho (cf. Stoljar 2005). Assim, um conceito fenomênico é um conceito as- 
sociado à perspectiva de primeira pessoa e a experiência é condição necessária para a sua aquisição. Por dependerem da experiência para serem adquiridos, conceitos fenomênicos são conceitualmente irredutíveis a conceitos físicos. Nesse sentido, saber como é ver o vermelho requer o conceito fenomênico adquirido quando se tem a experiência de vermelho.

Portanto, Loar concorda que existem conceitos subjetivos irredutíveis a conceitos físico-funcionais, porém, discorda que esses conceitos se refiram aos qualia defendidos por Jackson (1982; 1986). Loar (2002[1997], pp.298-9) propõe que, assim como conceitos físicos podem selecionar propriedades físicas diretamente, conceitos fenomênicos são conceitos que podem selecionar propriedades internas do nosso cérebro de modo direto. Ao termos uma experiência perceptiva de cor, adquirimos o conceito fenomênico dessa cor ao selecionarmos diretamente, via introspecção, determinada propriedade física-funcional do cérebro. Sobre a natureza dos conceitos fenomênicos, Loar (2002[1997], pp.298-9) os caracteriza como conceitos recognitivos peculiares da forma $x$ is one of that kind. Por exemplo, quando eu vejo a capa cor verde do livro que está a minha frente, tive a sensação $x$. Eu tenho o conceito fenomênico de $x$, se sei reconhecer $x$.

Em suma, conceitos físicos e conceitos fenomênicos podem selecionar essencialmente a mesma propriedade física, mas, a experiência é condição necessária para a formação de conceitos qualitativos. Sob esse ponto de vista, conceitos subjetivos não são capturados por um ponto de vista em terceira pessoa porque se referem a propriedades não-físicas, mas porque concepções objetivas não empregam conceitos subjetivos.

Aplicando a hipótese de Loar (2002[1997]) ao argumento do conhecimento, enquanto Mary estiver presa no seu quarto, ela não pode estabelecer a priori que a concepção física do vermelho e a concepção fenomênica do vermelho se referem ao mesmo fato físico. O conceito que Mary adquire com a sua experiência não está implicado por nenhum conceito físico-funcional, na medida em que o conceito fenomênico que ela adquire depende exclusivamente da sua introspecção do vermelho. Ao ver o vermelho pela primeira vez, Mary concebe como é ver o vermelho diretamente. Isso permite a essa objeção escapar da resposta que vimos contra a objeção de Tye (1986), haja vista que, conceitos físicos e conceitos fenomênicos se referem à mesma propriedade física sem serem mediados por um modo contingente de apresentação desta. E se ambos os conceitos selecionam a mesma propriedade de modo direto, pode-se defender que o conhecimento que Mary adquire com a sua experiência se refere a um fato físico que ela conhecia. Consequentemente, se Mary não aprende nenhum fato novo, a conclusão (6) do argumento do conhecimento não se sustenta.

Comparativamente, a estratégia dos conceitos fenomênicos de Loar (2002) parece-me mais forte que a hipótese de Tye (1986), pois explica a intuição de que os conceitos que formamos com base nas experiências conscientes são adquiridos de 
modo direto, sem recorrer aos qualia. E, ao atribuir estados cognitivos diferentes aos conceitos físicos e conceitos fenomênicos, explica o porquê pode parecer que os referentes dos conceitos fenomênicos não sejam propriedades físicas. Entretanto, muitos filósofos questionam essa estratégia contra o argumento do conhecimento.

Hill (2011) e Balog (2008, p.299) defendem que existe um fineness of grain na experiência que não pode ser capturado pelos conceitos fenomênicos. Nesse sentido, Hill (2001, pp.76-7) afirma que podemos formar conceitos gerais (vermelho, verde, azul, etc) e até conceitos mais determinados (azul-marinho, vermelho-coral, etc) que representam e nos ajudam na classificação das sensações, porém, a qualidade da experiência aparece à nossa consciência sempre de uma maneira altamente determinada. Quando Mary vê um objeto vermelho pela primeira vez, o vermelho aparece a ela com um matiz altamente determinado. Num segundo momento, ela vê outro objeto vermelho com um matiz diferente, e assim por diante. Mary pode ter um conceito geral que representa o vermelho, mas não um conceito que representa o vermelho da exata intensidade do vermelho que ela viu pela primeira vez. Dessa forma, Mary teve sensações de vermelho diferentes em cada uma das ocasiões, pois as qualidades fenomênicas das experiências foram diferentes. Decorre daí que, defender que o conceito físico do vermelho e o conceito fenomênico que Mary adquire ao ver o vermelho de um tomate maduro pela primeira vez se referem ao mesmo fato é desconsiderar a forma altamente determinada como a qualidade do vermelho aparece à consciência de Mary.

Loar (2002[1997], p.306) parece discordar da crítica de que Mary não pode ter o conceito fenomênico do exato tom de vermelho quando vê um tomate maduro, ao afirmar que estes conceitos podem ser de vários graus de generalidade; desde aqueles que se referem a uma qualidade altamente determinada até aqueles conceitos mais gerais.

Entretanto, como mostra Abath (2010), se os conceitos fenomênicos são recognitivos, não conseguimos explicar o que Mary adquire ao ver o vermelho pela primeira vez. Abath (2010, pp.89-90) se posiciona contra a estratégia de Loar (2002[1997]), fundamentando sua posição em evidências empíricas que sugerem que nós não somos capazes de reconhecer a maioria dos matizes específicos de cor com os quais entramos em contato; nem mesmo por um curto período de tempo após termos tido a experiência perceptiva. Se nós não conseguimos reconhecer a maioria dos matizes de cor, nós não temos conceitos recognitivos para a maioria dos matizes de cor. Assim, se conceitos fenomênicos são conceitos recognitivos, após Mary ver o vermelho pela primeira vez, é razoável afirmar que ela não possui o conceito fenomênico que se vincula à sensação de cor vermelha que ela teve quando viu o tomate maduro pela primeira vez, tendo em vista que ela não tem a capacidade recognitiva de reconhecer o aspecto fenomênico daquele vermelho. Portanto, se Mary não tem o conceito fenomênico que lhe permite reconhecer a sensação associada ao matiz do vermelho que 
ela viu pela primeira vez, a hipótese de Loar (2002[1997]) não explica o que Mary adquire com a experiência.

Mediante tais críticas, o que me parece certo é que conceitos fenomênicos não podem ser deduzidos a priori dos conceitos físicos, mas não que ambos os conceitos se referem à mesma propriedade. Se quisermos conciliar a experiência subjetiva com a estratégia dos conceitos fenomênicos, o desafio a ser enfrentado é explicar qual a natureza desses conceitos. Ao que parece, se adquirimos conceitos fenomênicos em nossas experiências, eles não são conceitos recognitivos. Por enquanto, não me parece convincente afirmar que a apreensão das qualidades de uma experiência envolve conceitualização. É mais razoável defender que há algo que não se reduz ao conceitual na percepção sensível. Se algo não se deixa apreender conceitualmente, a hipótese dos conceitos fenomênicos que vimos não é uma explicação adequada para o que Mary aprende com a sua experiência de cor, permitindo que se defenda que Mary aprende um novo fato ao ver o vermelho pela primeira vez.

Após pesarmos objeções e respostas aos tipos de materialismo a posteriori que vimos, parece-me que um dos méritos deste tipo de objeção é o de aceitar que Mary tem um ganho epistêmico ao ver o vermelho pela primeira vez sem conceder às conclusões antimaterialistas. Essa combinação explica parcialmente seu sucesso recente. Contudo, vimos que tais objeções não são fortes o suficiente para bloquear a conclusão antimaterialista do argumento do conhecimento.

\section{Terceiro tipo de objeção: Mary aprende um novo fato físico}

A objeção que veremos a seguir é fundamentalmente diferente das objeções que vimos, na medida em que, enquanto aquelas aceitam que Mary sabe todos os fatos físicos a respeito da visão humana antes de sair do quarto, Harman nega que uma pessoa que nunca viu a cor vermelha "poderia conhecer todos os fatos físicos e funcionais sobre a percepção de cor sem saber como é ver alguma coisa vermelha" (1990, p.44). Ainda que a pessoa tenha um conhecimento físico abrangente como o de Mary, ela não sabe como é o vermelho, pois desconhece o fato de que a percepção do vermelho tem um conteúdo representado específico. Desse modo, Harman (1990) concorda com Jackson $(1982 ; 1986)$ que Mary aprende novos fatos com sua percepção visual, mas discorda que estes sejam fatos não-físicos. Assim, essa objeção se opõe à premissa (4), isto é, que todos os fatos físicos sobre a visão humana são acessíveis pelo conhecimento que Mary adquire no quarto. Vejamos como ele fundamenta sua objeção.

No entender de Harman (1990), para que alguém saiba como é o vermelho, tem que ser capaz de representar o vermelho a si próprio, ou seja, saber como é a experiência de cor vermelha é representar para si a cor vermelha. Na medida em que Har-

Principia 20(3): 393-416 (2016). 
man (1990, p.44) adota a abordagem funcionalista segundo a qual o conteúdo das representações é determinado pelos conceitos contidos nesta, para que alguém possa representar o vermelho a si mesmo tem que ter o conceito apropriado do vermelho. ${ }^{11}$ Isso significa que uma pessoa que tem esse conceito está de certo modo funcionalmente determinada, de modo que isso só pode acontecer se a pessoa teve a experiência perceptiva de objetos vermelhos. Assim:

Eu afirmo que existe um fato funcional importante sobre a percepção de cores que uma pessoa cega não pode saber, isto é, que existe um conceito $R$ tal que, quando uma pessoa normal vê algo vermelho em boas condições de iluminação, ela tem uma experiência visual com uma estrutura representacional que contém este conceito $R$ (Harman 1990, p.45).

Então, se o papel funcional do conteúdo da experiência da cor vermelha depende do input perceptivo, o cego não conhece o fato necessário para que possa representar para si o vermelho do mesmo modo como alguém que já viu o vermelho, tendo em vista que aquele não foi fisicamente realizado. Desse modo, um cego de nascimento não pode saber como é algo vermelho, pois não tem o conceito apropriado para representar para si o vermelho. Embora ele possa saber, por exemplo, informações como a frequência de luz refletida que se refere à cor vermelha, ele depende da experiência perceptiva dessa cor para que forme representações que contenham o conceito $R$. A pessoa cega "não entende completamente o que é algo ser vermelho (...) porque ela não tem o conceito pleno de algo vermelho" (Harman 1990, p.45).

Transpondo o caso do cego para o experimento de Mary, antes de sair do quarto, Mary pode ter todo conhecimento físico sobre a visão humana, mas ela não pode saber como é ver o vermelho. Falta-lhe o conceito apropriado $R$ para que Mary possa representar para si o vermelho. Em outras palavras, Mary não conhece "todos os fatos funcionais, já que ela não sabe como funciona o conceito $R$ a respeito da percepção das coisas que são vermelhas" (Harman 1990, p.45). Para que Mary saiba como é ver o vermelho, é necessária uma experiência perceptiva dessa cor que lhe possibilitará aprender um novo fato sobre a visão humana. Ao sair do quarto, Mary vê o vermelho pela primeira vez e o papel funcional do conceito $R$ é fisicamente realizado. Ela aprende o fato de que a sua experiência visual tem um conteúdo representado específico. Ou seja, o estado funcional que Mary está ao ver o vermelho permite a ela saber um novo fato sobre o mundo, saber como é o vermelho.

Segundo Nida-Rümelin (2010), são poucos aqueles que defendem que Mary não pode conhecer todos os fatos físicos a partir do conhecimento físico que tem. Em crítica a essa estratégia de resposta fisicalista ao argumento do conhecimento, NidaRümelin (2010, p.15) afirma que se aceitarmos essa objeção, torna-se difícil compreender o que é ser um fato físico, pois a suposição de que fatos físicos são justamente aqueles fatos que podem ser expressos em terminologia física é abandonada. 
Para Ned Block (1997, pp.689-90), a objeção de Harman (1990) ao argumento do conhecimento pouco contribui para o debate sobre a existência dos qualia, pois continua plausível postular que Mary aprende fatos não-físicos com a sua experiência perceptiva. A sua argumentação, que reconstruiremos a seguir, consiste em mostrar que essa objeção não ataca a questão que está em jogo no argumento do conhecimento. Voltando ao cenário hipotético no qual Mary se insere, ela nunca viu a cor verde até que ela saia do seu quarto preto e branco. Então, como vimos, Harman (1990) defende que Mary não tem o conceito apropriado de verde para que possa representar para si o verde; esse conceito é fundamental para que ela tenha uma compreensão completa do que é algo ser verde. Faltando-lhe o conceito apropriado de verde, Mary pode dizer que azeitonas são verdes, porém, ela não tem esse conhecimento, "de fato, ela não pode sequer ter a falsa crença de que todas as azeitonas são verdes" (Block 1997, p.690). Ou seja, temos que aceitar que Mary não pode ter crenças sobre as cores até que as veja, pois não conhece o fato de que o conceito $R$ exerce um papel funcional na representação do verde.

Assim, segundo Block (1997, p.690), se aceitarmos a explicação de Harman (1990), o debate acerca dos qualia permanece. De um lado, os céticos dos qualia afirmam que Mary adquire um tipo de conhecimento de fatos (knowledge that) ao ver o verde pela primeira vez. De outro lado, os realistas dos qualia afirmam que Mary adquire dois tipos de conhecimento de fatos na primeira vez que ver o verde. Supondo que a teoria dos conceitos harmaniana esteja certa, ambos os lados podem aceitar que Mary adquire conceitos envolvendo conteúdos intencionais. Então, para os céticos dos qualia, Mary adquire o conceito apropriado de verde com a sua experiência visual, e "tendo lido na Enciclopédia Britânica que azeitonas são verdes, ela adquire o conhecimento que azeitonas são verdes" (Block 1997, p.690). E para os defensores dos qualia, além do conteúdo intencional, a experiência perceptiva de Mary também tem um conteúdo qualitativo.

Para a objeção de Harman (1990) eliminar a hipótese dos qualia seria preciso que ela excluísse a possibilidade de se atribuir conteúdos qualitativos adicionais aos conteúdos intencionais da experiência perceptiva. Ao deixar em aberto a discussão entre os representacionalistas que, como Harman (1990), afirmam que o conteúdo intencional da experiência é suficiente para explicar o seu caráter qualitativo, e aqueles que, como Block (1997), afirmam que o conteúdo das experiências não se resume ao conteúdo intencional, o debate sobre a existência dos qualia permanece. Desse modo, essa objeção não responde adequadamente ao argumento do conhecimento, por não atacar a questão central envolvida neste. Continua razoável defender que a experiência perceptiva que Mary tem ao ver o vermelho pela primeira vez envolve propriedades não-físicas.

Principia 20(3): 393-416 (2016). 


\section{Conclusão}

Vimos como o argumento do conhecimento parte de premissas epistêmicas para objetar o fisicalismo. A partir do hiato epistêmico entre o conhecimento físico que Mary adquire no quarto e o conhecimento fenomênico que ela adquire com a sua experiência de cor, infere-se um hiato metafísico entre consciência e matéria. Para mostrar essa passagem e tornar mais claro o que as objeções atacam no argumento do conhecimento, uma formalização desse argumento foi apresentada. A partir disso, tratamos de uma série de objeções que visaram derrubar a sua conclusão antimaterialista. $\mathrm{O}$ que se pode dizer destas?

Deve-se reconhecer que as objeções têm graus de força diferentes, de modo que umas são mais promissoras que outras. Distinguimos essas objeções em três tipos principais. Primeiro, as objeções que negam que Mary tenha um ganho epistêmico. A meu ver, essas objeções são as menos promissoras, pois atacam justamente o ponto mais forte do argumento do conhecimento. O segundo tipo de objeção aceita que Mary tenha um ganho epistêmico, mas ataca a ideia de que este conhecimento seria não-físico. Essas objeções são mais fortes que as do primeiro grupo, pois aceitam que Mary adquire um conhecimento novo com a sua experiência de cor. Porém, também não explicam satisfatoriamente as qualidades fenomênicas das experiências, dando brecha à hipótese dos qualia como propriedades irredutíveis ao físico. O terceiro tipo de objeção defende que Mary não pode conhecer todos os fatos funcionais sobre a experiência de ver a cor vermelha até que ela seja exposta a essa cor. Contudo, continua razoável defender que o conteúdo da experiência seja também composto por qualia, pois esta objeção não ataca o problema que está em jogo no argumento do conhecimento.

Portanto, diante do debate travado entre objeções e o que se disse em face destas, o argumento do conhecimento é bastante sólido e um notável desafio àquele que quer conciliar o caráter subjetivo das nossas experiências com o fisicalismo, haja vista que, nenhuma das objeções examinadas foi decisiva, isto é, nenhuma impediu a conclusão antimaterialista do argumento do conhecimento.

Desse modo, parece-me que a resposta mais razoável ao que Mary aprende ao ver a cor vermelha pela primeira vez é: Mary adquire conhecimento fenomênico com a sua experiência, um ganho epistêmico que não se reduz, nem pode se reduzir, a um dos conhecimentos físicos prévios que ela dispunha. Por enquanto, parece-me satisfatória a hipótese de que Mary aprende algo novo que é inexplicável de um ponto de vista estritamente físico.

Principia 20(3): 393-416 (2016). 


\section{Agradecimentos}

Meus agradecimentos a Plínio Smith, Osvaldo Pessoa Jr. e Claudemir Tossato pelas observações ao texto que deu origem a este artigo. Agradeço também aos pareceristas pelos seus comentários.

\section{Referências}

Abath, A. J. 2010. Physicalism and the nature of phenomenal concepts. Revista de Filosofia Aurora 22(30): 83-97.

Abrantes, P. 2005. Thomas Nagel e os limites de um reducionismo fisicalista. Cadernos de História e Filosofia das Ciências 15: 223-244.

Alter, T. 1998. A limited defense of knowledge argument. Philosophical Studies 90: 35-56.

- 2007. The Knowledge Argument. In: M. Velmans; S. Schneider (ed.) The Blackwell Companion to Consciousness, pp.396-405. Oxford: Blackwell Publishing.

Balog, K. 2009. Phenomenal Concepts. In: B. P. Mclaughlin; A. Beckermann; S. Walter (eds.) The Oxford handbook of philosophy of mind, pp.292-313.

Block, N. 1997. Inverted Earth. In: N. Block; O. Flanagan; G. Guzeldere (eds.) The Nature of Consciousness, pp.677-693. The MIT Press.

- 2002. Concepts of Consciousness. In: D. Chalmers (ed.) Philosophy of Mind, pp.206218. New York: Oxford University Press.

Braddon-Mitchell, D.; Jackson, F. 2007. Philosophy of Mind and Cognition. Oxford: Blackwell Publishing.

Broncano, F. 2007. La Mente Humana. Madrid: Editorial Trotta.

Chalmers, D. J. 1996. The Conscious Mind. New York: Oxford University Press.

Churchland, P. M. 1985. Reduction, Qualia, and the Direct Introspection of Brain States. Journal of Philosophy 82: 8-28.

Crick, F; Koch, C. 2003. A framework for consciousness. Nature neuroscience 6(2): 119-126. Dennett, D. C. 1991. The Consciousness Explained. New York: Back Bay Books.

Fish, W. 2010. Philosophy of Perception. New York: Routledge.

Gertler, B. 1999. A Defense of the Knowledge Argument. Philosophical Studies 93: 317-336.

- 2006. The Knowledge Argument. In: D. M. Borchert (ed.) Encyclopedia of Philosophy, v. 5, pp. 112-115. Macmillan.

Harman, G. 1990. The Intrinsic Quality of Experience. Philosophical Perspectives 4: 31-50.

Hill, C. S. 2011. Consciência. Trad. Alzira Allegro. São Paulo: UNESP.

Jackson, F. 1982. Epiphenomenal Qualia. Philosophical Quartely 32: 127-136.

—. 1986. What Mary didn't know. Journal of Philosophy 83(5): 291-295.

- 1998. Postscript on Qualia. In: F. Jackson (ed.) Mind, Method and Conditionals, pp.7679. London: Routledge.

- 2003. Mind and Illusion. In: A. O'hear (ed.) Minds and Persons, pp.251-271. Cambridge: Cambridge University Press.

- 2007. The Knowledge Argument, Diaphanousness, Representationalism. In: T. Alter;

S. Walter (eds.) Phenomenal Concepts and Phenomenal Knowledge, pp.52-64.

Kim, J. 1996. Philosophy of Mind. Cambridge: Westview Press.

Kripke, S. 1980. Naming and Necessity. Oxford: Blackwell Publishing.

Principia 20(3): 393-416 (2016). 
Kuhn, T. S. 2011[1970]. A Estrutura das Revoluções Científicas. Trad. Beatriz Vianna Boeira e Nelson Boeira. São Paulo: Perspectiva.

Lewis, D. 2002[1988]. What Experience Teaches. In: D. Chalmers (ed.) Philosophy of mind: Classical and Contemporary Readings, pp.281-294. New York: Oxford University Press.

Loar, B. 2002[1997]. Phenomenal States. In: D. Chalmers (ed.) Philosophy of mind: Classical and Contemporary Readings, pp.295-310. New York: Oxford University Press.

Nagel, T. 1974. What is it like to be a Bat? The Philosophical Review 82: 435-450.

Nida-Rümelin, M. 2010. Qualia: The Knowledge Argument. In: E. N. Zalta (ed.) Stanford Encyclopedia of Philosophy, pp.1-37.

Peacocke, C. 1983. Sense and Content. Oxford: Oxford University Press.

Polanyi, M. 1962. Tacit Knowing: its bearing some problems of philosophy. Reviews of Modern Physics 34(4): 601-616.

Seager, W.; Bourget, D. 2007. Representationalism about consciousness. In: M. Velmans; S. Schneider (eds.) Blackwell Companion to Consciousness, pp.261-276. Oxford: Blackwell Publishing.

Stoljar, D. 2005. Physicalism and Phenomenal Concepts. Mind and Language 20: 469-494.

Thomas, N. J. T. 1998. Mary doesn't know science: on misconceiving a science of consciousness. In: http://www.philpapers.org/rec/THOMDK.

Tye, M. 1986. Subjectives Qualities of Experience. Mind 95: 1-17.

. 2007. Philosophical Problems of Consciousness. In: M. Velmans; S. Schneider (eds.) Blackwell Companion to Consciousness, pp.23-35. Oxford: Blackwell Publishing.

DANIEL BORGONI

Universidade Federal de São Paulo.

Escola de Filosofia, Letras e Ciências Humanas.

Doutorando em Filosofia. CAPES.

dborgoni@hotmail.com

\section{Notas}

${ }^{1}$ Eventualmente poderei utilizar o termo 'materialismo' no lugar de 'fisicalismo'. Embora ambos os termos possam ter acepções bastante distintas, neste artigo, a acepção para ambos será aquela que está definida no texto para o fisicalismo.

2 Todas as citações deste artigo são traduções nossas.

${ }^{3}$ Por isso, o uso de um hipotético scanner cerebral que ajudasse Mary a identificar a banana pintada de azul ou o tomate vermelho não resolve a questão.

${ }^{4}$ Apresentado no encontro anual da divisão do pacífico da American Philosophical Association no dia 26 de março de 1998.

${ }^{5}$ Para uma definição de 'conhecimento tácito' ver Polanyi (1962, p.601).

${ }^{6}$ Sobre os exemplares, ver Kuhn (2011[1970], pp.234-5).

7 "É vital para nossa sobrevivência que nós sejamos capazes de selecionar padrões recorrentes. Reconhecer seu melhor amigo ou um tigre faminto exige a detecção de comunalidade (...) Se a teoria que a visão de cores evoluiu como um auxiliar para detecção de comida estiver correta, uma série de comunalidades ópticas não óbvias entre as coisas comestíveis e

Principia 20(3): 393-416 (2016). 
suas diferenças para o pano de fundo da floresta são os padrões para os quais a visão de cor evoluiu. Ora, comunalidades não óbvias como essas normalmente são detectadas somente depois de uma grande coleta e reunião de informação. A experiência de cor é, portanto, uma via totalmente incomum de adquirir de modo rápido informações relacionais e funcionais não óbvias" (Jackson 2003, p.262).

${ }^{8}$ Peacocke (1983) as nomeia de 'propriedades das sensações'.

9 Podemos encontrar objeção semelhante em Churchland (1985), porém, ele levanta essa objeção à posição de Nagel (1974). Contra o argumento do conhecimento, Churchland (1985) apenas faz a observação de que a sua objeção caberia àquele, mas não a explicita como faz com as objeções dele que analisamos neste artigo.

${ }^{10}$ Tye (1986) contextualiza o hiato epistêmico entre conhecimento físico-funcional e conhecimento fenomênico de outro modo. De um lado temos Jones, cego de nascença e cientista que detém todo conhecimento físico-funcional sobre a visão de cores e, de outro, Smith, um sujeito com visão normal, mas que desconhece os processos físicos da visão. Segundo Tye, Jones não saberia "que a experiência visual de Smith tem um conteúdo fenomênico $R$ " (1986, p.11). Após passar por uma cirurgia que lhe devolvesse a visão, Jones "viria a saber, por meio da experiência visual, que esta tem um conteúdo fenomênico determinado - aquele que Smith denomina $R$ " (Tye 1986, p.10). Contudo, embora aceite esse hiato epistêmico, ele defende que o conhecimento físico-funcional e o conhecimento fenomênico se referem ao mesmo fato físico.

${ }^{11}$ A teoria do conteúdo de Harman (1990, p.44) é baseada em seu artigo "(Non-Solipsistic) Conceptual Role Semantics" In: E.LePore (ed). New Directions in Semantics. London: Academic Press, pp.55-81, 1987.

Principia 20(3): 393-416 (2016). 